\title{
A Brief Study on the EQ Education for the Post-90 College Students
}

\author{
Xuelei Chen \\ School of Marxism, Hubei University of Chinese Medicine, \\ Wuhan City, PRC., 430065 \\ cxlhbtcm@163.com
}

\author{
Sa Wei* \\ School of Marxism, Hubei University of Chinese Medicine, \\ Wuhan City, PRC., 430065 \\ wshbtcm@163.com
}

\begin{abstract}
EQ is one of the essential qualities for human beings, which is of great importance for growth and cultivation of intellectuals. The college students in twenties grow up under the background of rapid growth of socialist market economy and the Internet. Their understandings of EQ and their EQ characteristics shown in the interpersonal communication are of great value for current exploration of the pathways of EQ education among the post-90s. Based on the importance and characteristics of EQ education, this article also tries to seek the countermeasures of EQ education for this special group.
\end{abstract}

Keywords-college students; post-90s, EQ education; importance; characteristics

\section{INTRODUCTION}

The Emotional quotient (EQ), as a psychological concept, refers to the human qualities in the aspects of emotion, affection, will, frustration, tolerance, etc., which mainly includes the strong abilities of self-cognition, self-motivation, emotional control, the ability of understanding other people's emotions as well as the organizational and communicational skills. As generally believed, EQ has a great influence on personal growth and success-higher EQ contributes a lot to personal academic or career success. At the celebration symposium on May 4th, 2013, when talking with the youth the significance of EQ, Chinese President Xi Jinping pointed out that "EQ plays an important role in doing the practical work".[1] Xi had stressed the weight of EQ on the one hand, and put forward new requirements for educators of higher institutions on the other. Against these backdrops, we believe it's important to have a further study on the EQ education for the college students.

\section{The Characteristics of the Post-90 College STUDENTS}

The college students in twenties are right at the essential turning point from teenagers to adults. They are showing unique characteristics in their EQ development.

\section{A. Strong Self-consciousness}

Growing up as the only child with the rapid development of the socialist market economy, the college students in twenties are a special group with obvious personalities, or, they have quite strong inter-generational self-consciousness, [2] which demonstrates the following features:
On the one hand, they are more confident. Because they grow up with the market economy, their material and cultural lives are relatively abundant compared with their parents, which contribute a lot to their self-confidence. In the meantime, their self-modesty is weakened as the market economy develops, for which has high requirement for equality and subjectivity. On the other, there are more selffocused. As the only child in the family, the environment and family education for them are quite different from their older generations. Their parents tend to educate them by generally giving encouragement, which makes them habitual to the central role in the family. Therefore, these post-90s often pay more attention to the subjective experience as individuals, realization of their own values and interests but insufficient attention to the collective values and interests.

\section{B. Insufficient Recognition of the EQ Education}

Different from the previous college students, the college students in twenties as an inter-generational group know well the importance of EQ for their development and success and pay a lot of attention to the cultivation of EQ. That's the reason why many of them choose to fight to join the students' union and other associations on campus. However, their understandings of EQ are not completely correct. First, they tend to simply take EQ as a communicational ability or skill. Secondly, they often pay too much attention to the upward communicational behavior but insufficient attention to the parallel communicational behavior. That's to say, they will make every effort to establish a good relationship with their teachers and the student leaders rather than the common classmates and peers, for which they wrongly believe it's an indication of higher EQ.

\section{Over-dependence on the Social Networking Soft-wares.}

As natives of the information age, the Internet and information technology have accompanied the whole process of their growth. For this, they are suffering an overdependence on the Internet and information, especially the diversified social networking soft-wares, which have exerted profound influence on their interactive ability with the outside world. Among this group, quite a few are indoors-boys and indoors-girls - they even order meals in their dorms, they don't walk out of here unless they have to go outside for classes, they almost carry out no communication with others in the real world, fully indulging themselves in the cyberspace. 
The above-mentioned situations truly do great harm to their EQ cultivation for lack of internal and external mechanisms.

\section{THE IMPORTANCE OF EQ EDUCATION FOR THE POST-90 COLLEGE STUDENTS}

Quite different from IQ (intelligence quotient), EQ measures a person's emotional intelligence, which is closely related to a person's ability to sense, understand and effectively apply the emotional power and sensitivity to push forward high levels of collaboration and productivity. No matter in the business or in study, EQ is fairly important because it helps effectively leverage the college students' awareness of emotions. A person's EQ score is often positively related to his or her success score.(see Fig. 1)[3] At present, EQ education will help the college students in twenties have a better understanding of the connotation of EQ, improve their adjustment to the new surroundings and personal communication skills, and in turn also facilitate the teachers' understandings of this inter-generational group.

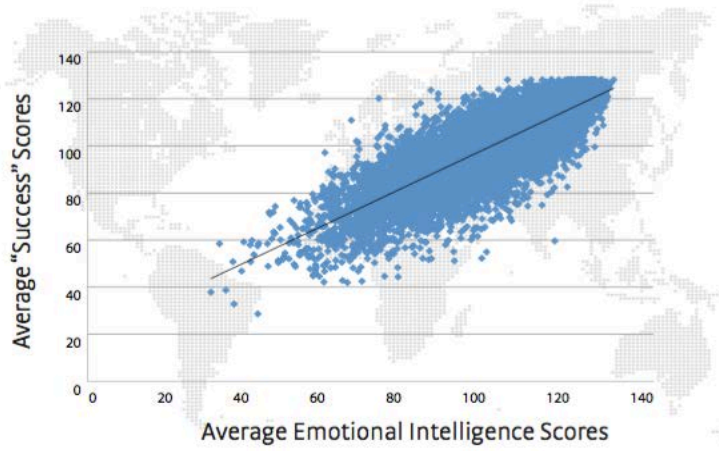

Fig. 1. EQ Score and Success Score

\section{A. Promoting the Formation of Right Understanding of EQ among the College Students}

There is no doubt that the college students are a special group with comparatively high IQs. However, IQ is not the only determinant of a person's success. In the socialist new era, EQ has shown greater importance for the college students in the process of growing and achieving success. In reality, the insufficient understandings even misunderstandings of EQ have existed extensively among the college students. [4] Many of them don't pay due attention to the practice and cultivation of EQ. Some of them even misunderstand that the personal EQ equals to the establishment of relational networks and securing advantages through influence, which makes many of them feel at loss when they cannot have their problems fixed satisfactorily in the real society. Some college students even do nothing to improve their EQ for in their eyes, EQ is an inborn quality. On the other hand, some other students hold that the ends justify the means--to have a higher EQ, they can sacrifice everything. Of course, these concepts of EQ are all misleading or even harmful. According to professor Martin Kilduff from University of Landon, excessive pursuit of EQ will also be harmful and lead a person to be more sophisticated when he or she enters the society in the future.[5] In this sense, a right understanding of EQ lays a solid foundation for the college students to appropriately behave on campus and in the society in future.

\section{B. Improving the College Students' Self-adjustment and Inter- personal Communication Abilities}

In effect, the college students are at the critical stage of growth and development, so it's necessary to train and coordinate their emotional adjustment so that they are able to meet the social requirements at present and in the future. [6] In the recent years, a series of campus tragedies have occurred on campuses in the mainland China, represented by the poisoning cases occurred in Beijing University and Fudan University, the homicide case of Ma Jiajue and often heard campus suicides. It can be seen from all these cases that the tragedy conductors have subjected themselves to such emotions as isolation, narrow-mindedness, impulse, anxiety and self-abasement in their inner hearts. Had not been resolved timely, all these emotions have interfered with their communication with others. Under these circumstances, they cannot pour their hearts and adjust themselves, which in turn leads to their solving intra-psychic conflicts with extreme means. What has been reflected here is that the EQ level of college students should be enhanced urgently. It's generally believed that the EQ education can help students foster correct self-cognition, self-control and self-adjustment, which in turn change their behavioral patterns of communication with others, get away from the negative emotions and emotional experience, face the pressure in a right way and keep a good psychological health. In this way, the campus tragedies will be fewer and the college students will grow in a much healthier way.

Having mainly stayed on campus from the elementary school to the college, the college students have little communication with the real society, leading to their relatively immature interpersonal communication with others. Such interpersonal communicational experience cannot make them fully adapt to the diversity and complexity of the society. As a single child and growing without equally competing and communicating with brothers or sisters, the post-90 college students generally have strong self-consciousness and weak independence, which has a negative impact on their interpersonal communicational patterns and qualities. Needless to say, the EQ education will help them better solve these problems.

\section{Facilitating the College Educators' Understanding of the College Students' EQ Characteristics}

There are three characteristics for this inter-generational group, that is, they are growing with the rapid development of socialist market economy, they are from the single-child family and they have been through the fast progress of information and popularization of cyber communication. Due to these facts, they are essentially different from their parents and teachers in the behavioral patterns, communicational styles, values, etc.. Therefore, we need to carry out an in-depth investigation into and analysis of the college students on the questions like what are the characteristics of their understandings of EQ, are their understandings scientific and how do their understandings of EQ affect their growth. On this basis, this paper is also trying to explore the rule of EQ 
education for the inter-generational group in order to provide a guide for EQ education on them.

\section{The COUnTERMEAsures of EQ EduCATION FOR THE POST- 90 COLLEGE STUDENTS}

\section{A. Having an In-depth Analysis and a Full Understanding of the Social Environment}

Having a full understanding and conducting an in-depth analysis of the social environment for the growth of this special group is the very basis and prerequisite for EQ education on them. The educators should pay more attention to the students' growing surroundings by putting themselves in the students' places, giving more care to their needs on the one hand and supporting them to foster the thanks-giving awareness on the other. [7] Only in this way can the educators truly perceive the students' inner thoughts, ideas and behavioral patterns and find breakthroughs in the EQ education.

\section{B. Guiding Them to Have a Right Understanding of the Connotation of EQ}

The college students in twenties have fostered a comparatively profound understanding of the importance of EQ. However, some of them are still not sufficiently rational and mature. As for the connotation of EQ, the fifth edition of the Modern Chinese Dictionary defines that "EQ refers to a person's emotional quality and his or her adaptability to the society in psychology." [8] The second edition of the Encyclopedia of China defines that "EQ refers to the ability of one person in controlling and managing his or her emotions." [9] We can see from the above that there are two aspects of the connotation of EQ, that is, EQ means self-cognition, selfcontrol and self-management internally and one's ability in interactive behavior and social adaptability externally. Only when the internal and external aspects are both taken into consideration can the students' understanding of $\mathrm{EQ}$ be comprehensive. In this case, a guideline should be formulated to urge them to have a better understanding of the connotation and requirements of EQ in the new era.

\section{Focusing More on the Collective Values in the EQ Education}

Handling the relationship between individuals and community in an appropriate way is an important aspect of the EQ education. The strong self-awareness and selfindependence of the college students in twenties help improve the innovation ability and literature of this special group. However, if their self-awareness and self-independence go extreme, they will not deal with the relationship between themselves and the community in a proper way. Compared with the previous college students, the post-90 college students attach more importance to their individual feelings and realization of individual interests. Under this circumstance, the teachers should try to pertinently cultivate and strengthen the students' awareness of collectivism. It's of great importance for these college students with high IQ to handle properly the relationship between individuals and the community.

In conclusion, in view of the extreme importance and the status quo of EQ education on the post-90 college students, more investigations should be conducted to make educators in colleges better realize the problems faced with the students, and more thoughts should be placed on the pathways of EQ cultivation and education for this special group. The EQ education for them, from a long-term perspective, is a huge project in which a multi-security system needs to be built.[10] That's to say, the society, the colleges, the teachers, and the students themselves all need to make some effort to do something to change the present situation.

\section{ACKNOWLEDGMENTS}

In the writing of this paper, professor $\mathrm{Hu}$ and some other colleagues have offered constructive suggestions in collecting and analyzing the materials. Thanks also go to the lovely students. Without the interaction with them and inspiration from them in the practical teaching, the completion of the paper is impossible.

\section{REFERENCES}

[1] Xi Jinping's remarks at a panel discussion with representatives of excellent young people from all walks of life, 2013-05-05. http://cpc.people.com.cn/n/2013/0505/c64094-21367227.html Chinese)

[2] Chen Zhu, Yu Xuelin, Investigation and Analysis of the Post-90 College Students Ideal and Faith Education. Journal of Hubei University of Science and Technology, vol. 39, p.33, 2019. (In Chinese)

[3] Six seconds, Emotional Intelligence and Success. 2019-03-12. https://www.6seconds.org/2019/03/12/white-paper-emotionalintelligence-and-success/.

[4] Li Luning, Wang Jinghui, Investigation and Analysis of the College Students' EQ and Educational Stattus. Journal of Jinzhou Medica University (Social Science Edition), vol.15, pp.118-123, 2017. (In Chinese)

[5] Li Xiuru, Jiang Hongbo, Misunderstandings of EQ Education among College Students and a Probe into the Methods of EQ Education. Education Teaching Forum, no.47, p.36, 2018. (In Chinese)

[6] Luan Chunyu, On the Acting Points of College Educators in the Political and Ideological Education based on EQ Cultivation of College Students. Ideological and Political Education Research, vol. 32, p.73, 2016. (In Chinese)

[7] Zhang Jinghui, Study on the EQ Cultivation of Contemporary College Students. Economists, 02, pp.53-54, 2018. (In Chinese)

[8] The Linguistics Institute of Chinese Academy of Social Sciences Modern Chinese Dictionary (fifth edition).Beijing: The Commercial Press, 2007, p.1116. (In Chinese)

[9] Encyclopedia of China (second edition). Beijing: Encyclopedia of China Publishing House, 2009, p.195. (In Chinese)

[10] Gong Guangjun, Establishment of a Multi-security System of EQ Education among College Students. Sichuan Labor Security, 01, pp.103104, 2018. 